\title{
Investigating Electronic Nicotine Delivery Systems (Ends) Use Amongst Telephone Quitline Participants
}

\author{
Lukowski A* and Olson $\mathrm{K}$ \\ Health Initiatives, National J ewish Health, USA \\ *Corresponding author: Lukowski AV, Health \\ Initiatives, National J ewish Health, 1400 J ackson Street, \\ S113, Denver, CO 80206, USA
}

Received: January 20, 2017; Accepted: February 14, 2017; Published: February 16, 2017

\begin{abstract}
Introduction: Tobacco cessation quitlines are effective in helping smokers quit. With recent classification of Electronic Nicotine Delivery Systems (ENDS) as a tobacco product further investigation is needed to understand the impact of ENDS on quit attempts. ENDS products have increased in popularity for a variety of reasons including public policies aimed at protecting others from secondhand smoke and claims that they aid in cessation. This report compares the proportion of quitline participants using ENDS products from those that do not.

Methods: National Jewish Health collected data from numerous state and corporate quitlines. Participants were separated into three groups including participants using only ENDS products (EcigO), participants using both ENDS and cigarettes (E\&Cig) and participants using cigarettes but no ENDS products (CigO). Enrolled participants are eligible to receive up to 5 coaching sessions and 8 weeks of Nicotine Replacement Therapy (NRT).

Results: Both EcigO and E\&Cig reported similar reasons for ENDS use, however, EcigO use ENDS more frequently compared to E\&Cig $(X=317.619$, $\mathrm{p}$-value<.0001). EcigO completed more coaching calls ( $F$-Value $=86.85$, $p$-value $<.0001)$, had significantly higher proportion of males $(X=109.86$, $p$-value $<.0001)$ and were more likely to have a college education ( $x=1029.48$, p-value<.0001) compared to E\&Cig and CigO.
\end{abstract}

Conclusions: These findings highlight the increased use of ENDS year over year within a telephonic quitline population. Furthermore it outlines how this population differs from the traditional tobacco users and may need tailored coaching to quit both traditional tobacco and ENDS products.

Keywords: E-cigarettes; Electronic Nicotine Delivery Systems; Quitline; Telephone cessation

\section{Introduction}

Electronic Nicotine Delivery Systems (ENDS) products were introduced into the market in 2007 and have seen steady growth in prevalence across all populations. ENDS have been marketed primarily as a replacement to combustible products, an option to use when traditional products cannot be used (i.e., where clean indoor air policies have been instituted), and as a cessation tool [1]. The prevalence of these products has grown steadily and significantly year over year since their introduction, across age groups with the most significant uptake by middle and high school students [2,3]. Current national trends for ENDS use show prevalence around 3.5\% and $58.8 \%$ used ENDS products in addition to cigarettes [3]. However, ENDS have yet to pass the scientific and regulatory rigor required to be deemed a proven cessation aid or the data to be considered a safe product [4]. In addition, the FDA recently deemed ENDS as tobacco products in May 2016, providing more regulations than ever before [3]. Even with these latest regulations, there are still several outstanding questions for the public health community about how to about how to best help all populations to be completely tobacco free [5]. That coupled with the lack of significant data to support tobacco industry marketing claims call on the tobacco control community to better understand prevalence, use patterns and reasons for ENDS use.

\section{The Current Study}

One of the most successful evidence-based treatment modalities for tobacco cessation is telephonic (and Web-supported) quitlines, which offer education, support, phone coaching, and nicotine replacement therapy for most callers [6]. Available in all U.S. States since 2002, telephonic quitlines typically offer a combination of coaching and nicotine replacement therapy (NRT) to populations who want to quit tobacco $[7,8]$. These services are available to anyone in the U.S. and are available at low to no cost. For the general population, a recent Cochrane review found that proactive telephonic services help smokers to quit compared to brief counseling or selfhelp materials [7].

Since quitlines primary audience is to help tobacco users with cessation, they are well positioned to understand ENDS as well as other tobacco use behaviors in this population. In the current study, we report on data from National Jewish Health (NJH), which provides telephonic cessation services for 17 states along with various corporate and health plan clients. Our primary aim is to examine how ENDS users compare to non-ENDS users across the 
Table 1: ENDS Questions included in Intake.

\begin{tabular}{|c|c|c|}
\hline 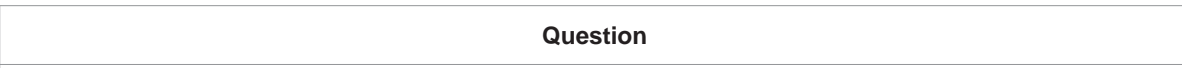 & Response Options & $\begin{array}{l}\text { First Recorded } \\
\text { Year }\end{array}$ \\
\hline $\begin{array}{l}\text { Do you currently use E-Cigarette/Vapor/Electronic Nicotine Delivery Systems (ENDS) in combination with (a) } \\
\text { tobacco product/s every day, some days, or not at all? }\end{array}$ & $\begin{array}{ll}- & \text { Yes } \\
- & \text { No } \\
-\quad & \text { Don't Know } \\
\text { - } & \text { Refused }\end{array}$ & 2015 \\
\hline $\begin{array}{l}\text { Do you currently use E-Cigarette/Vapor/Electronic Nicotine Delivery Systems (ENDS) every day, some days, } \\
\text { or not at all? }\end{array}$ & $\begin{array}{ll}- & \text { Every Day } \\
\text { - } & \text { Some Days } \\
\text { - } & \text { Not at all } \\
\text { - } & \text { Don't Know } \\
& \text { Refused }\end{array}$ & 2013 \\
\hline Do you use an e-cigarette/e-vaping product that contains nicotine? & $\begin{array}{ll}- & \text { Yes } \\
\text { - } & \text { No } \\
\text { - } & \text { Don't Know } \\
\text { - } & \text { Refused }\end{array}$ & 2014 \\
\hline Do you use e-cigarette cartridges or a tank system? & $\begin{array}{ll}-\quad & \text { Cartridge } \\
& \text { Tank }\end{array}$ & 2016 \\
\hline Electronic or e-cigarettes & $\begin{array}{ll}- & \text { Yes } \\
\text { - } & \text { No } \\
\text { - } & \text { Don't Know } \\
& \text { Refused }\end{array}$ & 2011 \\
\hline Have you used an e-cigarette or other electronic vaping product in the past 30 days? & $\begin{array}{ll}- & \text { Yes } \\
- & \text { No } \\
- & \text { Don't Know } \\
- & \text { Refused }\end{array}$ & 2013 \\
\hline How soon after you wake, do you first smoke an e-cigarette? & $\begin{array}{ll}- & \text { Within five minutes } \\
\text { - } & 6 \text { to } 30 \text { minutes } \\
\text { - } & 31 \text { to } 60 \text { minutes } \\
\text { - } & \text { More than } 60 \text { minutes } \\
\text { - } & \text { Don't know } \\
\text { Refused }\end{array}$ & 2013 \\
\hline $\begin{array}{l}\text { People use e-cigarette/e-vaping products for a variety of reasons, are you currently using e-cigarettes/e- } \\
\text { vaping products to quit smoking? }\end{array}$ & $\begin{array}{ll}- & \text { Yes } \\
- & \text { No } \\
- & \text { Don't Know } \\
- & \text { Refused }\end{array}$ & 2014 \\
\hline $\begin{array}{l}\text { What would you say is your reason for using E-Cigarette/Vapor/Electronic Nicotine Delivery Systems } \\
\text { (ENDS)? }\end{array}$ & 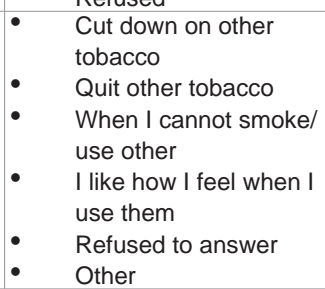 & 2014 \\
\hline Do you intend to quit using e-cigarettes (usually within 30 days)? & $\begin{array}{ll}- & \text { Yes } \\
- & \text { No } \\
- & \text { Don't Know } \\
- & \text { Refused }\end{array}$ & 2013 \\
\hline
\end{tabular}

following domains: demographic characteristics, dual use of tobacco products, and time of first use. A better understanding of the unique characteristics of quitline callers who use ENDS may help direct future best clinical practices for a tobacco using quitline population. This analysis compares three defined groups including ENDS only users (EcigO), dual ENDS and cigarette users (E\&Cig) and cigarette only users (CigO). A majority of participants who report using ENDS products also report cigarette use. Participants were excluded from the analysis if they did not answer "yes" or "no" to questions regarding use of ENDS products or Cigarettes.

Quitlines started collecting some data on ENDS use in 2011 but the questions have evolved just as ENDS products have changed and we learn more about prevalence. The percent of overall participants using the quitline that reported ENDS use increased from 2.85\% in 2011 to $8.11 \%$ in 2016 . Knowing the reasons for use is a critical part of understanding prevalence; therefore we collect information in this area. See Table 1 for questions and possible responses which include the reasons why participants use ENDS.

\section{Methods}

\section{Sample Selection}

NJH has been a quitline service provider since December 2002, and has served approximately 1.3 million participants across 18 states, several corporations, and numerous health plans. $\mathrm{NJH}$ collected data regarding ENDS from 17 state quitlines and various employer or health plan groups(Alabama, Arkansas, Idaho, Massachusetts, Michigan, Montana, Nevada, New Hampshire, North Dakota, Ohio, Rhode Island, Utah, Iowa, Kentucky, Pennsylvania, Wyoming, Colorado, Vermont; $n=293,257$ ) over a 5 year period from October 1, 2011 and September 30, 2016. This time period was selected because of implementation of the ENDS questions into an NJH case management system (Table 2).

\section{Measures}

Quitline intake assessment: Participants who enrolled in the quitline program completed minimal data set (MDS) questions recommended by North American Quitline Consortium (NAQC). 
Table 2: Demographic Characteristics for Sample.

\begin{tabular}{|c|c|c|c|}
\hline \multirow[b]{2}{*}{ State } & \multicolumn{3}{|c|}{ Number of participants } \\
\hline & $\begin{array}{l}\text { ENDS Only } \\
\text { (EcigO) }\end{array}$ & $\begin{array}{l}\text { Dual User } \\
\text { (E\&Cig) }\end{array}$ & $\begin{array}{l}\text { Cigarette Only } \\
\text { (CigO) }\end{array}$ \\
\hline Vermont & 22 & 283 & 5200 \\
\hline Alabama & 63 & 1182 & 17595 \\
\hline Arkansas & 46 & 879 & 11699 \\
\hline Colorado & 296 & 3974 & 72130 \\
\hline Idaho & 3 & 44 & 1976 \\
\hline lowa & 2 & 83 & 1048 \\
\hline Kentucky & 56 & 823 & 14311 \\
\hline Massachusetts & 29 & 305 & 5943 \\
\hline Michigan & 48 & 503 & 1751 \\
\hline Montana & 70 & 833 & 20513 \\
\hline Nevada & 22 & 312 & 3473 \\
\hline New Hampshire & 11 & 130 & 1830 \\
\hline North Dakota & 26 & 438 & 7897 \\
\hline Ohio & 106 & 1342 & 27670 \\
\hline Pennsylvania & 175 & 5649 & 37643 \\
\hline Rhode Island & 6 & 94 & 1156 \\
\hline Utah & 69 & 538 & 11494 \\
\hline Wyoming & 36 & 590 & 5764 \\
\hline $\begin{array}{l}\text { Employer or Health } \\
\text { plan }\end{array}$ & 221 & 1146 & 23706 \\
\hline Total & 1310 & 19148 & 293257 \\
\hline
\end{tabular}

The MDS, consisting of 18 questions is collected from eligible callers at intake. Eligibility requires residency of the state offering the program. Question categories include reasons for calling and awareness of the quitline, tobacco behaviors and caller characteristics (e.g., demographics, health status). Included in the intake are questions related to ENDS and responses are presented in Table 1.

\section{Quitline program}

Intake to coaching: The standard telephonic quitline treatment consists of an intake that includes the ENDS questions and up to five coaching calls with the opportunity for additional calls throughout the program. NJH's clients have differing offerings of quit medications ranging from none to nicotine patches only to multiple forms of NRT (i.e., including gum and lozenges. These offerings change based on funding and participant eligibility. Multiple states also offered prescription medications (i.e., bupropion, varenicline) sometime during the 5 year period including Montana and Wyoming.

\section{Statistical analysis}

Data were analyzed using a combination of Microsoft Excel (v.2013) and statistical analysis system (SAS, version 9.3). Descriptive statistics were evaluated by ENDS status (ECigO, E\&Cig and CigO). Differences in average age and number of coaching calls completed were evaluated using an ANOVA test between the three study groups followed by Tukey's Studentized Range test to determine significance between individual groups. Proportions for demographic characteristics and tobacco use patterns were evaluated using chisquare analysis. Statistical assumptions were reviewed and accounted for in this analysis.

\section{Results}

\section{ENDS use reasons and dependence level}

Quitline participants identify many reason for utilizing ENDS products but the top three include "Quit other tobacco", "Cut down on other tobacco" and "For times when the participant cannot smoke or use other tobacco". These reasons stayed consistent regardless of the participant's tobacco use patterns as an EcigO or E\&Cig participant.

EcigO participants use e-cigarettes more frequently compared to E\&Cig participants. EcigO participants reported everyday use $22.52 \%$ of the time compared to $8.64 \%$ of E\&Cig participants ( $\chi=317.619$, p-value<.0001). E\&Cig participants also have their time to first use later in the day, but this metric was not statistically significant due to low response rate. A potential cofounder for the first time to use metric for E\&Cig participants pertains to first time of cigarette use. While these participants may use the ENDs product later in the day, E\&Cig participants (48.89\%) were slightly more likely to smoke a cigarette within five minutes of waking compared to $\mathrm{CigO}$ participants $(48.41 \%)\left(\chi=1.07^{\star} 10^{7}, \mathrm{p}\right.$-value $\left.<.00001\right)$. The time to first use of tobacco product upon waking is a standard proxy based on the Fagerström Test for Nicotine Dependence (FTND) [9] for dependence level in a tobacco using population, so thus may indicate a lower addiction level for EcigO users.

\section{Quitline engagement}

One of the ways that quitlines measure level of engagement in participants is the utilization of coaching services as measured by the number of coaching calls completed by an individual when participating in a telephone coaching program. EcigO participants appear to utilize coaching at a higher rate compared to dual and cigarette only participants. EcigO participants completed an average of 2.28 coaching calls compared to E\&Cig participants (1.1.63) and CigO participants (1.70). The differences is average number of coaching calls were statistically significant $(\mathrm{df}=2, \mathrm{~F}-\mathrm{Value}=86.85$, p-value<.0001). With further post hoc analysis using Tukey's Studentized Range test for the average number of coaching calls it is determined that the mean number of coaching calls differs between all group combinations.

\section{Demographics}

The overall gender distribution of quitline callers is typically $60 \%$ women and 40\% men. As shown in Table 3, the EcigO participants (43.84\%) had significantly higher proportion of male compared to E\&Cig participants (34.81\%) and CigO participants $(38.40 \%)$ $(\chi=109.86$, $\mathrm{p}$-value $<.0001)$.

The average age of the entire sample was 46.09 years of age, E\&Cig participants were the youngest (44.29) average group followed by CigO (46.21) and ECigO (46.36). The differences is average age were statistically significant $(\mathrm{df}=2, \mathrm{~F}-$ Value $=170.54$, $\mathrm{p}$-value $<.0001)$. With further post hoc analysis using Tukey's Studentized Range test for the average age it is determined that the mean ages differ between all group combinations except $\mathrm{ECigO}$ and $\mathrm{CigO}$.

ECigO participants were more likely to have a college education (22.06\%) compared to E\&Cig (17.55\%) and CigO (16.31\%) 


\begin{tabular}{|c|c|c|c|c|}
\hline Demographics & & $\begin{array}{l}\text { ENDS only } \\
\text { User }\end{array}$ & $\begin{array}{l}\text { Dual } \\
\text { User }\end{array}$ & $\begin{array}{c}\text { Cigarette } \\
\text { only }\end{array}$ \\
\hline Age $^{*}$ & Average Age & 46.362 & 44.279 & 46.214 \\
\hline \multirow{4}{*}{ Age Grouped* } & Young Adult (18-30) & $16.58 \%$ & $20.89 \%$ & $17.22 \%$ \\
\hline & Adult (31-45) & $28.57 \%$ & $12.91 \%$ & $28.13 \%$ \\
\hline & $\begin{array}{l}\text { Middle adulthood } \\
(46-60)\end{array}$ & $38.04 \%$ & $35.91 \%$ & $38.81 \%$ \\
\hline & Older adulthood $(61+)$ & $16.81 \%$ & $30.29 \%$ & $15.84 \%$ \\
\hline \multirow{2}{*}{ Sex* } & Female & $56.16 \%$ & $65.19 \%$ & $61.60 \%$ \\
\hline & Male & $43.84 \%$ & $34.81 \%$ & $38.40 \%$ \\
\hline $\begin{array}{l}\text { N. Coaching } \\
\text { Calls* }\end{array}$ & $\begin{array}{c}\text { Average N. Coaching } \\
\text { Calls }\end{array}$ & 2.189 & 1.746 & 1.766 \\
\hline \multirow{6}{*}{ Education* } & $\begin{array}{l}\text { High School Degree } \\
\text { or GED }\end{array}$ & $24.96 \%$ & $34.11 \%$ & $36.15 \%$ \\
\hline & Some College & $28.93 \%$ & $31.27 \%$ & $28.62 \%$ \\
\hline & College Degree & $22.06 \%$ & $17.55 \%$ & $16.31 \%$ \\
\hline & $\begin{array}{l}\text { Less than high school } \\
\text { degree }\end{array}$ & $10.00 \%$ & $14.59 \%$ & $16.68 \%$ \\
\hline & No Response & $14.05 \%$ & $2.48 \%$ & $2.23 \%$ \\
\hline & $\begin{array}{l}\text { Trade/Vocational } \\
\text { school }\end{array}$ & $0.00 \%$ & $0.01 \%$ & $0.02 \%$ \\
\hline \multirow{6}{*}{$\begin{array}{l}\text { Insurance } \\
\text { Levels* }\end{array}$} & Uninsured & $31.07 \%$ & $26.43 \%$ & $31.47 \%$ \\
\hline & Commercial & $20.69 \%$ & $19.65 \%$ & $21.06 \%$ \\
\hline & Medicaid & $18.85 \%$ & $22.86 \%$ & $21.49 \%$ \\
\hline & Medicare & $14.66 \%$ & $15.09 \%$ & $14.24 \%$ \\
\hline & Other & $11.07 \%$ & $14.56 \%$ & $10.39 \%$ \\
\hline & Don't Know & $3.66 \%$ & $1.42 \%$ & $1.35 \%$ \\
\hline
\end{tabular}

*Indicates significant difference between the groups at $p<.05$.

participants. The percentage of participants in a higher level of education by study group was significant ( $\chi=1029.48$, $p$-value $<.0001)$

There were also differences in insurance coverage amongst the three study groups. EcigO participants reported being uninsured (31.07\%) more than E\&Cig (26.43\%) but similar to CigO (31.47\%). E\&Cig participants were most likely to be insured through Medicaid (22.86\%) compared to EcigO (18.85\%) and CigO (21.49\%). When evaluating insurance groups to study population there was a significant difference in the proportions $(\chi=535.37$, $p$-value $<.0001)$.

\section{Discussion}

ENDS products are becoming increasingly prevalent among current combustible tobacco users as well as those who have never used tobacco products $[2,3]$. Callers to tobacco quitlines provide an opportunity to understand ENDS use patterns in this population. The current study looks at one of the largest U.S. quitline databases to better understand how ENDS users compare to non-ENDS users in demographics and prevalence. These findings will contribute to knowledge about the use patterns of current tobacco users who access tobacco quitlines.

Quitline participants that utilize both ENDS and Cigarette products tend to be similar to cigarette only users, but notable differences arise when reviewing participants that reported ENDS use without cigarette use. ENDS only participants are more likely to be male and have a college education. This unique demographic profile provides insight into how to the ENDS population differs from a quitline perspective and potential barriers in their attempt to quit tobacco products.

E\&Cig participants, who are sometimes, consider dual tobacco users, demonstrated time to first use of ENDS later in the day compared with EcigO and CigO. It is important to note that these users did demonstrate time to first cigarette significantly earlier than ENDS, thus potentially speaking to a difference in dependence level between ENDS and combustible products [10,11]. Another potential reason for this difference is that ENDS products physiologically impact the brain differently than combustible products, providing more of a quick hit to nicotinic receptors in the brain [11].

EcigO and E\&Cig participants showed no difference in their rationale for ENDS use, indicating the two of the top three reasons as cessation focused (i.e., "quit other tobacco") or harm reduction (i.e., "cut down on other tobacco"). The reasons endorsed by participants help inform quitline practices to continue to continue to work with participants on cessation and/or harm reduction from all tobacco products because these are their reasons for using these products. It also allows quitline staff to provide participants with information on evidence-based cessation practices that include coaching and quit medication combined. On the other hand, the third reason endorsed by ENDS users (i.e., "For times when the participant cannot smoke or use other tobacco") highlights a growing fear from the health community. This is the fear that dual use of products will reduce the urgency to quit tobacco products [11], which has ramifications for continued prolonged use which has the potential for long-term health effects [12].

Other data that demonstrates consistency with cessation or harm reduction as primary motivators is how ENDS users engage with a quitline cessation program. These results show that EcigO participants utilize telephone coaching at a significantly higher rate compared to E\&Cig and CigO users. This data is consistent with previous studies that found that ENDS users more frequently cite cessation as their primary motivation for using ENDS products [1316] which highlights a difference in motivation. This motivation has the potential to impact quitline participants' progress and potential success in a telephone quitline cessation program. Furthermore, the EcigO group may have been previous dual users who have moved to EcigO prior to entering the quitline program. Since EcigO participants maybe further in their quit attempt compared to E\&Cig and CigO participants another possibility for the higher program engagement may be that EcigO users may have a lower dependence level on ENDS products overall compared with more traditional ones.

\section{Limitations}

One possible limitation to this study is that there is likely a selection bias with the participants. Due to the fact that participants who enroll and utilize a telephonic quitline program may be very different from those individuals who choose not to call, potentially limiting the generalizability of study findings. For example, the average profile of a quitline participant is female, over 45 years of age and has been utilizing tobacco products for more than ten years.

\section{Conclusion}

ENDS use has increased in both the general population and the 
$\mathrm{NJH}$ quitline population, with rates even higher in these tobacco users. Better understanding the needs of tobacco users who use ENDS products is crucial to continued understanding of use patterns overall. The characteristics for this large, multistate sample of quitline callers has important implications for further investigation and informing the broader tobacco community about ENDS use patterns in a quitline population. This data has the potential to inform more targeted and tailored cessation strategies for all ENDS users.

\section{References}

1. Etter JF, Bullen C. Electronic cigarette: users profile, utilization, satisfaction and perceived efficacy. Addiction. 2011; 106: 2017-2028.

2. King BA, Patel R, Nguyen K, Dube SR. Trends in Awareness and Use of Electronic Cigarettes among U.S. Adults, 2010-2013. Nicotine Tob Res. 2014: $17: 219-227$

3. Quick Stats: Cigarette Smoking Status Among Current Adult E-cigarette Users, by Age Group-National Health Interview Survey, United States, 2015. MMWR Morb Mortal Wkly Rep. 2016; 65: 1177.

4. Wollscheid KA, Kremzner ME. Electronic cigarettes: safety concerns and regulatory issues. Am J Health-Syst Ph. 2009; 66: 1740-1742.

5. Hartmann-Boyce J, McRobbie H, Bullen C, Begh R, Stead LF, Hajek P. Electronic cigarettes for smoking cessation. Cochrane Database Syst Rev 2016: 9

6. Fiore MC, Jaen CR, Baker TB, et al. Treating Tobacco Use and Dependence: 2008 Update. Clinical Practice Guideline. Rockville, MD: U.S. Department of Health and Human Services, Public Health Service; 2008.

7. Stead LF, Hartmann-Boyce J, Perera R, Lancaster T. Telephone counselling for smoking cessation. Cochrane Database Syst Rev. 2013; 8: CD002850.
8. Zhu SH, Anderson CM, Tedeschi GJ, et al. Evidence of real-world effectiveness of a telephone quitline for smokers. N Engl J Med. 2002; 347: 1087-1093.

9. Heatherton TF, Koslowski LT, Frecker RC, Fagerström K-O. The Fagerström Test for Nicotine Dependence: a revision of the Fagerström Tolerance Questionnaire. Br J Addict. 1991; 86: 1119-1127.

10. Brown J, Beard E, Kotz D, Michie S, West R. Real-world effectiveness of e-cigarettes when used to aid smoking cessation: a cross-sectional population study. Addiction. 2014; 109: 1531-1540.

11. Grana R, Benowitz N, Glantz SA. E-cigarettes: a scientific review. Circulation 2014; 129: 1972-1986.

12. US Dept of Health and Human Services. The Health Consequences of Smoking-50 Years of Progress. A Report of the Surgeon General. Atlanta, GA: US Department of Health and Human Services, CDC; 2014

13. Delnevo CD, Giovenco DP, Steinberg MB, et al. Patterns of electronic cigarette use among adults in the United States. Nicotine Tob Res. 2016 18: 715-719.

14. Adkison SE, O'Connor RJ, Bansal-Travers M, et al. Electronic nicotine delivery systems: international tobacco control four-country survey. Am J Prev Med. 2013; 44: 207-215.

15. Goniewicz ML, Lingas EO, Hajek P. Patterns of electronic cigarette use and user beliefs about their safety and benefits: an internet survey. Drug Alcohol Rev. 2013; 32: 133-140.

16. Zhu S-H, Gamst A, Lee M, et al. The use and perception of electronic cigarettes and snus among the U.S. population. PLoS One. 2013; 8: e79332.
J Fam Med - Volume 4 Issue 2 - 2017

ISSN : 2380-0658 | www.austinpublishinggroup.com

Lukowski et al. (C) All rights are reserved
Citation: Lukowski A and Olson K. Investigating Electronic Nicotine Delivery Systems (Ends) Use Amongst Telephone Quitline Participants. J Fam Med. 2017; 4(2): 1108. 